\title{
Miocardite chagásica em caninos no Estado do Rio Grande do Sul
}

\author{
Chagasic myocarditis in dogs in Rio Grande do Sul \\ Saulo Petinatti Pavarini' ${ }^{\mathrm{I}}$ Eduardo Conceição de Oliveira' ${ }^{\mathrm{I}}$ Paulo Mota Bandarra ${ }^{\mathrm{I}}$ \\ Juliano Souza Leal ${ }^{\mathrm{I}}$ Eufrosina Setsu Umezawa ${ }^{\mathrm{II}}$ Daniela Bernadete Rozza ${ }^{\mathrm{III}}$ \\ David Driemeier $^{\mathrm{I}^{*}}$
}

\begin{abstract}
Neste trabalho, são relatados dois casos de morte súbita por doença de Chagas aguda em caninos da zona rural de Porto Alegre, Rio Grande do Sul, Brasil. Os cães, um macho Pit Bull com nove meses (canino 1) e uma fêmea Labrador Retriever com dois anos (canino 2), morreram em janeiro de 2005 e maio de 2008, respectivamente. As necropsias revelaram aumento cardíaco em ambos os casos. O coração do canino 2 apresentou formato globoso com múltiplas áreas pálidas na musculatura cardíaca, mais evidentes no ventrículo direito e câmaras cardíacas dilatadas, principalmente as da direita. Ao exame histológico, ambos os casos apresentaram alterações semelhantes caracterizadas por infiltrado inflamatório difuso não-purulento acentuado, predominantemente linfocitário intersticial. Nas fibras miocárdicas, havia grande número de pseudocistos, repletos de formas amastigotas do Trypanosoma cruzi. Ao teste sorológico TESA-blot, amostra do canino 2 foi positiva para anticorpos IgM e IgG anti-T.cruzi, achado característico da fase aguda da miocardite chagásica. Os resultados indicam que a doença de Chagas deve ser investigada em casos de morte súbita em cães na região Sul do Brasil e que a espécie pode servir como reservatório e sentinela da doença em humanos.
\end{abstract}

Palavras-chave: miocardite, cães, Trypanosoma cruzi.

\section{ABSTRACT}

Acute Chagas disease caused sudden death in two dogs from Porto Alegre rural zone of, Rio Grande do Sul, southern Brazil. A 9-month-old Pit Bull male (dog 1) and a 2year-old Labrador Retriever female (dog 2) died in January 2005 and May 2008, respectively. At necropsy, the hearts were enlarged. In $\operatorname{dog} 2$, heart was remarkably globoid with multiple pale areas scattered in the myocardium, especially in the right ventricle. Heart chambers, especially in the right side, were dilated. Histological findings were similar in both cases and consisted of diffuse non suppurative myocarditis predominantly with lymphocytic interstitial infiltrates. Within myocardial fibers were observed pseudocysts filled with amastigotes forms of Trypanosoma cruzi. Serologic test TESA-blot resulted positive in samples from dog 2 and showed IgM e IgG anti-T.cruzi antibodies characteristic of acute Chagas disease. The results indicate that Trypanosoma cruzi infection must be considered in the differential diagnosis of sudden death in dogs in southern Brazil and that the specie may act as a reservoir and sentinel for the disease in human beings.

Key words: chagasic myocarditis, dogs, Trypanosoma cruzi

A doença de Chagas é causada pela infecção com o protozoário Trypanosoma cruzi, tem grande importância em humanos e é um dos maiores problemas sanitários da zona rural das Américas Central e do Sul. A doença é transmitida, principalmente, pelas fezes dos insetos vetores da família Reduviidae, subfamília Triatominae (SHOFIELD \& DIAS, 1991; PRATA, 1994).

\footnotetext{
IDepartamento de Patologia Clínica Veterinária, Universidade Federal do Rio Grande do Sul (UFRGS). Av. Bento Gonçalves 9090, 91540-000, Porto Alegre, RS, Brasil. E-mail: davetpat@ufrgs.br. *Autor para correspondência.

IIInstituto de Medicina Tropical de São Paulo, Departamento de Medicina Preventiva, Faculdade de Medicina, Universidade de São Paulo (USP), São Paulo, SP, Brasil.

IIIUniversidade Estadual Paulista (Unesp), Araçatuba, SP, Brasil.
} 
Os cães também podem ser infectados com T. cruzi por meio do contato com fezes de vetores (triatomíneos) infectados depositadas nos locais da mordedura do vetor, em abrasões na pele ou nas mucosas. A infecção também pode ocorrer por via oral, pela ingestão de vetores ou tecidos de reservatórios silvestres infectados com o T. cruzi. As transmissões por via transplacentária e por amamentação já foram descritas em cães (YAEGER, 1971; BARR et al., 1995).

A doença de Chagas é caracterizada por três fases. A fase aguda é caracterizada por disfunção miocárdica resultante de miocardite com grande número de pseudocistos (formas amastigotas) nas fibras musculares cardíacas. Durante essa fase, podem-se observar inúmeros T.cruzi (forma tripomastigota) na corrente sangüínea, possibilitando diagnóstico pelo método direto por meio de preparações citoscópicas de sangue. (WILLIAMS et al., 1977 ; BARR et al., 1989; BARR et al., 1991; MEURS et al., 1998). A fase latente ou crônica indeterminada ocorre quando o animal sobrevive à fase aguda e está associada à ausência de sinais clínicos e parasitemia não-detectável. A fase crônica sintomática pode ser associada com miocardite crônica e focos de fibrose e pode culminar em insuficiência cardíaca congestiva (BARR et al., 1989; BARR et al., 1991; MEURS et al., 1998).

Além das manifestações cardíacas, cães infectados com $\boldsymbol{T}$. cruzi podem apresentar manifestações neurológicas devido à encefalite induzida pelo protozoário (WILLIAMS et al., 1977; BERGER et al., 1991).

Os cães têm sido considerados importantes reservatórios domésticos de $\boldsymbol{T}$. cruzi em países da América Latina. Além disso, servem como sentinelas para detectar a infecção em humanos (GURTLER et al., 1991; CASTANERA et al., 1998; CRISANTE et al., 2006).

O objetivo deste trabalho é relatar dois casos fatais da doença de Chagas aguda em caninos que viviam na cidade de Porto Alegre, Rio Grande do Sul. Além disso, ressaltam-se as alterações patológicas associadas com a doença.

Um cão Pit Bull macho de nove meses de idade (canino 1) e uma fêmea Labrador Retriever de dois anos de idade (canino 2) foram enviados ao Setor de Patologia Veterinária da Universidade Federal do Rio Grande do Sul (SPV-UFRGS), respectivamente, em janeiro de 2005 e maio de 2008. Os animais viviam em propriedades rurais localizadas na cidade de Porto Alegre, Estado do Rio Grande do Sul, região Sul do Brasil. Os dados da evolução da doença e sinais clínicos foram obtidos com os proprietários e veterinários responsáveis pelos animais.
As amostras de tecidos, coletadas durante as necropsias, foram fixadas em $10 \%$ de formol em solução tamponada, desidratadas em concentrações crescentes de álcool etílico, diafanizadas em xilol, incluídas em parafina e cortadas. Cortes de $5 \mu \mathrm{m}$ foram posteriormente corados pela técnica de hematoxilina e eosina (HE)

Amostras de sangue do canino 2 foram coletadas para detecção de anticorpos anti-T. cruzi pelo teste sorológico confirmatório para doença de Chagas TESA-blot (UMEZAWA et al., 1996). Esse teste Immunoblotting utiliza membranas de nitrocelulose contendo exoantígenos de formas tripomastigotas de T. cruzi (TESA=trypomastigote excreted-secreted antigens) que foram incubadas com soro do canino 2 diluído a $1 / 100$. A reação foi positiva para anticorpo anti- T. cruzi das classes G e M, quando incubados com conjugado peroxidase anti-cão (Sigma Co.) e revelados com 4-cloro-napthol (UMEZAWA et al, 1996).

O canino 1 foi encontrado morto sem sinais prévios de doença, caso em que houve suspeita de envenenamento. No pátio da propriedade, freqüentemente eram encontrados Didelphis marsupialis (gambás), que são reconhecidos reservatórios silvestres do $\mathbf{T}$. cruzi.

No dia do óbito do canino 2, este foi alimentado normalmente às $8 \mathrm{~h}$ e às $11 \mathrm{~h}$. Posteriormente foi encontrado morto e não havia manifestado sinais clínicos prévios. Três meses antes da morte do canino 2, outro cão Labrador Retriever com 2 anos de idade morreu nessa mesma propriedade após haver apresentado sinais clínicos de insuficiência cardíaca. Há registro anterior à ocorrência desses óbitos de que o proprietário, suspeitando da presença de barbeiros (triatomíneos), solicitou uma inspeção à defesa sanitária, cuja visita ao local não identificou nenhum triatomíneo.

Durante a necropsia do canino 1, foram identificados: bom estado corporal, congestão generalizada de órgãos, espuma abundante na traquéia e coração globoso com câmaras cardíacas dilatadas. No exame externo do canino 2, foram detectados: mucosas oral e oculares pálidas, linfonodos (axilares, mesentéricos e poplíteo) e timo aumentados e com coloração vermelho-escura. No saco pericárdio, havia aproximadamente $15 \mathrm{ml}$ de líquido translúcido (hidropericárdio). O coração apresentava formato globoso, com petéquias multifocais no epicárdio e múltiplas áreas pálidas na musculatura cardíaca (Figura 1A), afetando principalmente o ventrículo direito (Figura 1B). As câmaras cardíacas estavam dilatadas, especialmente o átrio e o ventrículo direito. Fígado e 


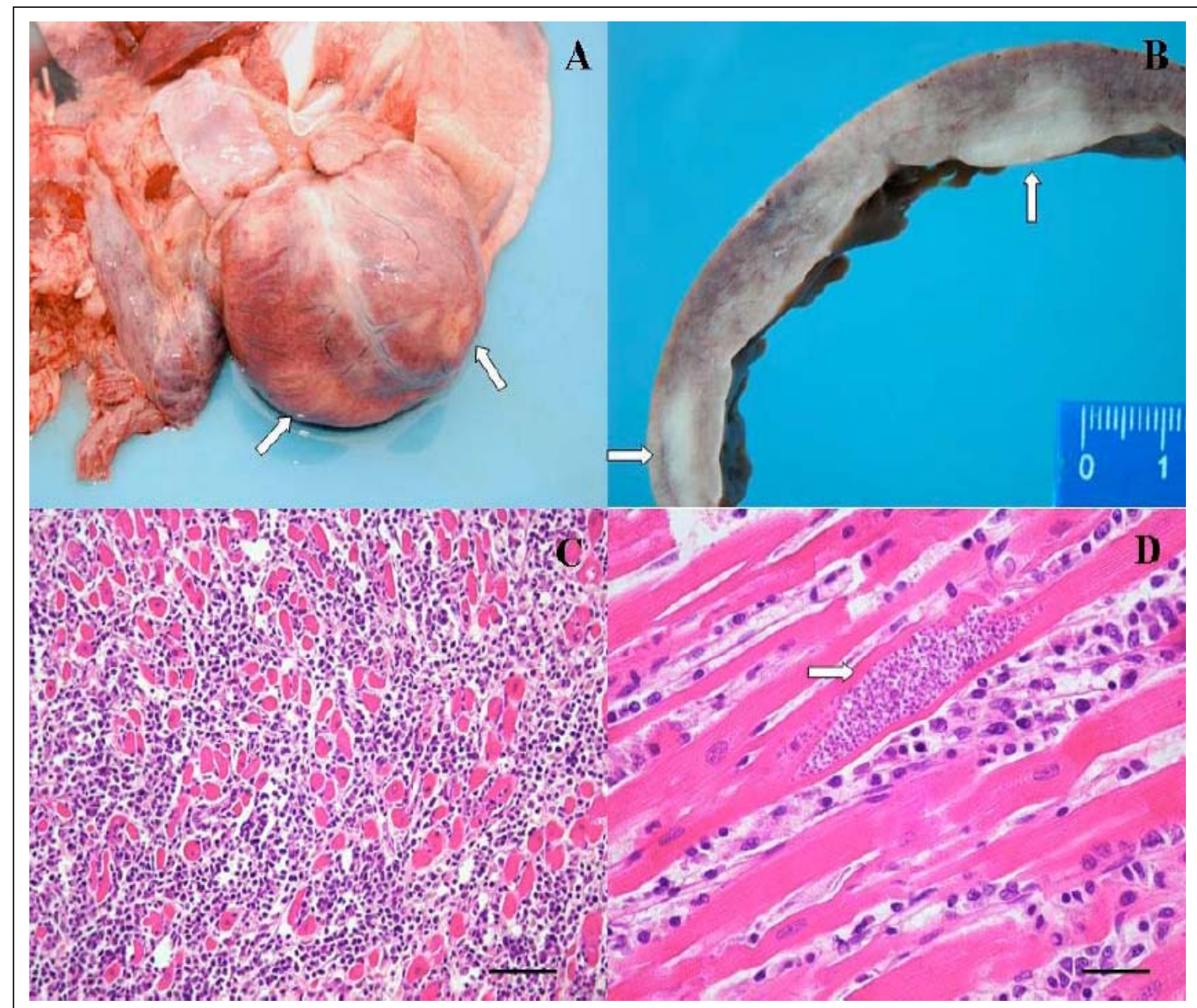

Figura 1 - A. Miocardite por doença de Chagas em um cão. Coração com formato globoso e múltiplas áreas pálidas na musculatura (setas). B. Canino com miocardite chagásica apresentando ventrículo direito com áreas pálidas na musculatura cardíaca (setas). C. Miocardite chagásica em um canino, infiltrado inflamatório difuso composto principalmente por linfócitos. HE Barra: $100 \mu \mathrm{m}$. D. Miocardite chagásica em canino, fibra muscular cardíaca com pseudocisto repleto de formas amastigotas de T. cruzi. HE Barra: 50 $\mu \mathrm{m}$.

baço apresentavam coloração vermelho-escura com bordos arredondados.

Ao exame histológico, havia infiltrados inflamatórios difusos acentuados, compostos em sua maioria por linfócitos e, em menor quantidade, histiócitos, plasmócitos e neutrófilos (Figura 1C) nos corações dos dois casos. Grande número de fibras musculares cardíacas apresentava estruturas compatíveis com pseudocistos repletos de formas amastigotas de $\boldsymbol{T}$. cruzi (Figura 1D). O infiltrado era mais acentuado no ventrículo e no átrio direito. Foram também observados focos de necrose e discreta degeneração das fibras cardíacas. No esôfago, estômago e intestino havia infiltrado linfocitário multifocal leve na camada muscular (canino 1 e 2) e ganglioneurite mioentérica mononuclear leve (canino 2). Os linfonodos estavam congestos com hiperplasia linfóide acentuada. No fígado, pulmão e baço, foi observada congestão difusa acentuada e, no pulmão, foi observado edema acentuado. Nos demais órgãos não foram visualizadas alterações.

Amostras do canino 2 foram positivas no teste TESA-blot para anticorpos anti-T. cruzi das classes IgG e IgM, com a detecção das bandas SAPA características da fase aguda da doença de Chagas (UMEZAWA et al., 1996)

O diagnóstico de doença de Chagas aguda nos caninos 1 e 2 foi estabelecido com base nos achados de necropsia e exames histopatológicos. No canino 2, o diagnóstico foi confirmado pela detecção de anticorpos IgM anti-T. cruzi, característico da fase aguda.

Em caninos, as alterações macroscópicas e microscópicas são achados característicos de casos 
agudos da doença de Chagas. A maior concentração de lesões no coração direito, como observado nesses casos, é tipicamente relatada nessa doença. As células predominantes na miocardite eram linfócitos, não se observando fibrose concomitante. Alterações como as descritas nesses dois casos e a deteç̧ão de pseudocistos de $\boldsymbol{T}$. cruzi são características da fase aguda da doença de Chagas (BARR et al., 1991; CALIARI et al., 2002).

A detecção de anticorpos IgM anti-T. cruzi no soro do canino 2, pelo teste TESA-blot (UMEWZAWA et al., 1996), confirma que esse cão se encontrava na fase aguda da doença de Chagas.

A maioria dos casos fatais da doença de Chagas aguda em cães é diagnosticada por ocasião da necropsia devido à rápida evolução da doença. Alterações como letargia, linfadenopatia generalizada, mucosas pálidas, aumento no tempo de reperfusão capilar, hepatomegalia, esplenomegalia e anormalidades eletrocardiográficas têm sido relatadas (BARR et al., 1991; MEURS 2005). Conforme o relato dos proprietários, nos dois casos, os animais morreram subitamente. A história clínica também incluía mucosas pálidas. O aumento generalizado de linfonodos, hepatomegalia e esplenomegalia foi constatado apenas na necropsia.

A doença de Chagas tem sido relatada em diferentes raças de cães. Embora não tenha sido observada predileção racial, uma maior freqüência de casos tem sido observada em raças esportivas e de trabalho, principalmente Labrador Retriever e Pointer. Essa maior prevalência da doença de Chagas provavelmente está associada com o estilo de vida dos animais dessas raças e seus hábitos insetívoros. Os ambientes rurais em que esses animais viviam favoreciam o contato com vetores infectados e hospedeiros vertebrados silvestres infectados (KJOS et al., 2008).

A miocardite chagásica deve ser considerada como causa de morte súbita em cães no Estado do Rio Grande do Sul, Brasil. Este trabalho alerta para a possibilidade da existência de pessoas expostas (em contato ou convivendo nos mesmos ambientes) a hospedeiros infectados com o protozoário T. cruzi, causador da doença de Chagas.

\section{REFERÊNCIAS}

BARR, S.C. et al. Chronic dilatative myocarditis caused by Trypanosoma cruzi in two dogs. Journal of the American Veterinary Medical Association, v.195, p.1237-1241, 1989.
BARR, S.C. et al. Clinical, clinicopathologic, and parasitologic observations of trypanosomiasis in dogs infected with North American Trypanosoma cruzi isolates. American Journal of Veterinary Research, v.52, p.954 -960, 1991.

BARR, S.C. et al. Trypanosoma cruzi infection in Walker Hounds from Virginia. American Journal of Veterinary Research, v.56, p.1037-1044, 1995.

BERGER, S.L. et al. Neurologic manifestations of trypanosomiasis in a dog. Journal of the American Veterinary Medical Association, v.198, p.132-134, 1991.

CALIARI, M.V. et al. Immunohistochemical studies in acute and chronic canine chagasic cardiomyopathy. Virchows Archiv, v.441, p.69-76, 2002. Disponível em: <http:// www.springerlink.com/content/0jupr7342whqv1cm/>. Doi: 10.1007/s00428-001-0542-4.

CASTANERA, M.B. et al. Evaluation of dogs as sentinels of the transmission of Trypanosoma cruzi in a rural area of northwestern Argentina. Annals of Tropical Medicine and Parasitology, v.92, p.671-683, 1998.

CRISANTE, G. et al. Infected dogs as a risk factor in the transmission of human Trypanosoma cruzi infection in western Venezuela. Acta Tropica, v.98, p.247-254, 2006. Disponível em: $<\mathrm{ht} \mathrm{t}$ p:// w w w. s c i e n c ed i r e c t. c o m / science?_ob=ArticleURL\&_udi=B6T1R-4K7WJC0$1 \&$ _user $=687358 \&$ _rdoc $=18 \_\mathrm{fmt}=$ \&_orig $=$ search\&_sort $=$ d \& view = c \&_a c ct $=$ C $000037899 \&$ _version $=1 \&$ _ u r l Versio n $=0 \&$ _ u s e r i d $=68$ 7358\&md5=ab4107f13ed34b4dc15d147d29cd0b3c>. Doi: 10.1016/j.actatropica.2006.05.006.

GURTLER, R.E. et al. Chagas disease in north-west Argentina: infected dogs as a risk factor for the domestic transmission of Trypanosoma cruzi. Transactions of the Royal Society of Tropical Medicine Hygiene, v.85, p.741-745, 1991. Disponível em: < http://www.sciencedirect.com/ science?_ob=ArticleURL\&_udi=B75GP-4C0K8TKS 4\&_user $=687358 \&$ \&doc $=1 \&$ _fmt $=\&$ _orig $=$ search \&_sort $=\mathrm{d} \&$ view $=\mathrm{c} \&$ _acct $=\mathrm{C} 000037899 \&$ _version $=1 \&$ _ u r l Versio n $=0 \&$ _ us e ri d $=687358$ $\& \mathrm{md5}=035 \mathrm{a} 28 \mathrm{a} 9 \mathrm{ba85}$ cdf64edfcb9d9034e3c0>. Doi: 10.1016/ 0035-9203(91)90440-A.

KJOS, S.A. et al. Distribution and characterization of canine Chagas disease in Texas. Veterinary Parasitology, v.152, p. 249-256, 2008. Disponível em: http://www.sciencedirect.com/ science?_ob=ArticleURL\&_udi=B6TD7-4RS3TNK$1 \&$ _user $=687358 \&$ \&doc $=1 \&$ _fmt $=$ \&_orig $=$ search \& sort $=$ d \& vi e w = c \&_a c c t $=$ C $000037899 \&$ _ v e rsion $=1 \&$ _ url Version $=0 \&$ _ us e ri d $=$ 687358\&md5=774183b5596881a13bdfa1dfdc79ad32. Doi: 10.1016/j.vetpar.2007.12.021.

MEURS, K.M. et al. Chronic Trypanosoma cruzi infection in dogs; 11cases (1987-1996). Journal of the American Veterinary Medical Association, v.213, p.497-500, 1998. 
MEURS, K.M. Primary myocardial disease in the dog. In: ETTINGER, S.J.; FELDMAN, E.C. Textbook of veterinary internal medicine. St. Louis: Mosby Elsevier Saunders, 2005. Cap.203, p.1077-1072.

PRATA, A. Chagas'disease. Infectious Diseases Clinics of North America, v.8, p.61-76, 1994.

SHOFIELD, C.J.; DIAS, J.C.P. A cost benefit analysis of Chagas' disease control. Memorias do Instituto Oswaldo Cruz, v.86, p.285-295, 1991.
UMEZAWA, E.S. et al. Immunoblot Assay using excretedsecreted antigens of Trypanosoma cruzi in serodiagnosis of congenital, acute, and chronic Chagas' disease. Journal of Clinical Microbiology, v.34, p.2143-2147, 1996.

WILLIAMS, G.D. et al. Naturally occurring Trypanosomiasis (Chagas disease) in dogs. Journal of the American Veterinary Medical Association, v.171, p.171-177, 1977.

YAEGER, R.G. Transmission of Trypanosoma cruzi infection to opossums via the oral route. Journal of Parasitology, v.57, p.1375-1376, 1971. 